Jurnal Ilmu Ilmu Agribisnis: Journal of Agribusiness Science, 9(1), Februari 2021

\title{
PENGAMBILAN KEPUTUSAN DAN POLA PEMBELIAN BUMBU GILING PADA RUMAH TANGGA DI KOTA BANDAR LAMPUNG
}

\author{
(Decision Making and Purchase Pattern of Household Consumers on Ground Spices \\ in Kota Bandar Lampung)
}

Elisa Sijabat, Wuryaningsih Dwi Sayekti, Dyah Aring Hepiana Lestari

Jurusan Agribisnis, Fakultas Pertanian, Universitas Lampung, Jl. Prof. Dr. Soemantri Brojonegoro No. 1

Bandar Lampung 35145, e-mail: wuryaningsih.dwisayekti@fp.unila.ac.id

\begin{abstract}
The purposes of this research are to determine the decision making process, purchasing patterns, and dominant factors in purchasing ground spices in Kota Bandar Lampung. This research was conducted in Pasir Gintung market, Tugu market, and Cimeng market. There were 90 housewife respondents drawn using accidental sampling method. Ground spices, as the object of this research, consisted of "sayur santan", "rendang" and "ungkep" spices. Data were analyzed descriptively and using Principal Component Analysis (PCA) factor analysis. The results showed that housewives decided to buy ground spices by the process of needs introduction, information searching, alternative evaluation, purchase decision, and postpurchase evaluation. The pattern of ground spices purchases by housewives was that the amount of spice purchased in the past week was IDR2,000.00- IDR5,500.00, the most type purchased was "rendang" with the frequency of 1-2 times a week. The dominant factors on purchasing decisions was formed by three main factors based on the value of the loading factors. The first, influence factor, consisted of variables colour, taste, influence of other people, confidence of making seasoning by their own, and confidence in taste of ground spices. The second, perception factor, consisted of variables perception of the price compared to the amount of ground spices obtained, perception of the price compared to that of packaged ground seasoning, and aroma of ground spices. The third, display of ground spices business, consisted of variables cleanliness of the product, the place, and friendliness of traders.
\end{abstract}

Key words: factor, ground spices, purchase

\section{PENDAHULUAN}

Indonesia merupakan salah satu negara di Asia Tenggara yang perekonomiannya didominasi oleh sektor pertanian dan perkebunan. Berdasarkan BPS Provinsi Lampung (2017), sektor pertanian di Indonesia terus memberi kontribusi positif untuk perekonomian Indonesia. Sektor pertanian sampai saat ini berperan penting bagi penduduk Indonesia karena sebagian besar penduduk Indonesia bermatapencaharian sebagai petani. Terdapat 6 (enam) macam subsektor pertanian, yaitu hortikultura, kehutanan, perikanan, perkebunan, pertambangan, peternakan, dan tanaman pangan. Setiap subsektor memiliki komoditas pertanian yang berbeda-beda namun seluruh komoditas pertanian yang ada berpengaruh terhadap kehidupan penduduk Indonesia.

Beberapa komoditas pertanian seperti cabai, bawang merah, bawang putih dan tomat merupakan sebagian dari komoditas yang banyak digunakan untuk dijadikan sebagai bahan penyedap rasa pada makanan atau biasa disebut dengan bumbu, di mana bumbu tersebut berguna untuk menambah cita rasa makanan khas Indonesia. Bumbu menjadi faktor utama dalam pembuatan suatu makanan yang lezat. Menurut Prihastuti, Komariah, dan Purwanti (2008), bumbu adalah suatu bahan untuk mempertinggi aroma makanan tanpa mengubah aroma bahan alami. Manfaat dari bumbu adalah merangsang nafsu makan, membantu pencernaan makanan, dan sebagai bahan pengawet makanan.

Perubahan hidup masyarakat yang semakin maju, telah mengubah kebutuhan masyarakat yang menginginkan segala sesuatu dalam bentuk instan, termasuk juga dengan kebutuhan bumbu yang menyebabkan perubahan pada bentuk produk bumbu menjadi lebih instan. Bumbu di pasar ada dalam berbagai bentuk yaitu bumbu basah dan bumbu bubuk. Bumbu basah merupakan bumbu yang masih segar, yang dapat dikelompokkan menjadi dua macam yaitu bumbu utuh atau belum digiling dan bumbu giling basah, sedangkan bumbu bubuk merupakan bumbu basah yang dikeringkan. 
Saat ini bumbu giling basah banyak dijual di pasar tradisional khususnya di pasar tradisional Kota Bandar Lampung. Berdasarkan pengamatan yang telah dilakukan, jumlah pedagang yang menjual bumbu giling basah di pasar tradisional juga semakin meningkat. Bumbu giling basah dianggap penting bagi sebagian masyarakat karena dapat membantu meringankan pekerjaan rumah tangga dalam membuat suatu makanan yang memerlukan waktu yang cukup banyak jika harus meracik bumbu sendiri, oleh karena itu bumbu giling basah memiliki peran penting bagi konsumen terkhusus ibu rumah tangga. Pengambilan keputusan rumah tangga dalam mengonsumsi bumbu giling basah dapat menyebabkan adanya proses pembelian bumbu giling basah, di mana kegiatan pembelian bumbu giling basah akan menghasilkan pola pembelian atau pola konsumsi bumbu giling basah pada rumah tangga. Penelitian ini akan membatasi jenis bumbu giling basah yang akan diteliti yaitu bumbu sayur santan, bumbu rendang dan bumbu ungkep. Pola pembelian bumbu giling basah oleh rumah tangga dapat dipengaruhi oleh beberapa faktor seperti faktor pribadi, faktor sosial faktor psikologis, dan faktor kualitas (Kotler 2005).

Berdasarkan uraian tersebut maka tujuan penelitian ini adalah untuk mengetahui proses pengambilan keputusan dalam mengonsumsi bumbu giling basah pada rumah tangga, mencermati pola pembelian bumbu giling basah dan menganalisis faktor dominan terhadap pembelian bumbu giling basah pada rumah tangga di Kota Bandar Lampung.

\section{METODE PENELITIAN}

Penelitian ini dilakukan dengan menggunakan metode survai di beberapa pasar tradisional di Kota Bandar Lampung. Pasar tradisional yang dijadikan lokasi penelitian adalah Pasar Pasir Gintung, Pasar Tugu, dan Pasar Cimeng yang ditentukan berdasarkan purposive sampling. Pertimbangan pemilihan lokasi penelitian adalah ketiga pasar tersebut memiliki jumlah pedagang bumbu giling basah yang lebih banyak dibandingkan dengan pasar tradisional lain. Pengumpulan data dilakukan pada bulan Maret--Mei 2019.

Setiap pasar tradisional yang menjadi lokasi penelitian ditetapkan satu pedagang bumbu giling basah sehingga terdapat tiga pedagang bumbu giling basah pada tiga pasar tradisional. Penetapan pedagang tersebut dilakukan agar konsumen memiliki persepsi terhadap produk bumbu giling basah yang sama. Pedagang bumbu giling basah yang menjadi sampel dalam penelitian ini ditentukan dengan meminta kesediaan untuk dijadikan tempat penelitian. Pedagang bumbu giling basah diteliti untuk mendapatkan informasi mengenai komposisi bumbu giling basah, ukuran atau takaran untuk setiap bumbu giling basah yang diteliti dan juga untuk mengetahui bagaiamana proses pembuatan bumbu giling basah.

Setelah menentukan sampel pedagang pada setiap pasar yang menjadi lokasi penelitian, hal selanjutnya yang dilakukan adalah menentukan jumlah sampel konsumen untuk setiap pasar tradisional. Jumlah populasi rumah tangga yang membeli bumbu giling basah di lokasi penelitian tidak diketahui, sehingga penentuan sampel dilakukan dengan metode accidental sampling. Menurut Cohen, Manion, dan Morrison (2007), jumlah batas minimal sampel yang diambil dalam penelitian yaitu sebanyak 30 sampel, maka penelitian ini mengambil masing-masing 30 sampel pada setiap pasar tradisional sehingga total terdapat 90 sampel konsumen yang menjadi responden dalam penelitian ini. Responden yang diteliti adalah responden yang pernah membeli atau mengonsumsi jenis bumbu giling basah. Bumbu giling basah yang menjadi fokus utama dalam penelitian ini, yaitu bumbu sayur santan, bumbu rendang dan bumbu ungkep.

Data yang digunakan dalam penelitian ini adalah data primer dan sekunder. Data primer diperoleh melalui wawancara langsung dengan menggunakan daftar pertanyaan (kuesioner) yang sudah dipersiapkan dan melalui pengamatan. Data primer yang dimaksud dalam penelitian ini adalah data gambaran umum responden dan pedagang, data perilaku rumah tangga dalam memutuskan untuk membeli bumbu giling basah dan data pola pembelian bumbu giling basah. Khusus data jumlah pembelian bumbu giling basah ditanyakan dengan cara mengingat kembali (recall) pembelian bumbu giling basah pada satu minggu terakhir. Data sekunder dalam penelitian ini adalah data dari Badan Pusat Statistik Provinsi Lampung yang berupa data rata-rata konsumsi dan jumlah pengeluaran per kapita kabupaten/kota di Provinsi Lampung.

Sebelum melakukan pengumpulan data, dilakukan uji validitas dan reliabilitas pada kuesioner untuk beberapa variabel yang akan diuji, yaitu variabel persepsi harga bumbu giling basah dengan barang yang diperoleh, persepsi harga bumbu giling basah dengan harga bumbu giling sachet, pengaruh orang lain, pengaruh rasa, warna produk, aroma/bau 
produk, kebersihan, keramahan pedagang, dan kepercayaan diri terhadap rasa bumbu giling basah, kepercayaan diri dalam meracik bumbu sendiri. Variabel pendapatan, pekerjaan dan jumlah anggota keluarga tidak diuji validitas dan realibitasnya karena ketiga variabel tersebut tidak diukur dengan menggunakan skor. Dalam melakukan uji validitas dan realibilitas digunakan skala likert dengan memberi rentang skala yang terdiri dari 5 sampai dengan 1 . Menurut Singarimbun dan Effendi (2006), jumlah minimal uji coba kuesioner dilakukan terhadap 30 responden. Dengan jumlah minimal 30 responden maka distribusi nilai akan lebih mendekati kurve normal. Setelah dilakukan uji validitas dan reliabilitas didapatkan hasil bahwa seluruh variabel valid dengan nilai Cronbach Alpha sebesar 0,72 yang berarti kuesioner penelitian reliabel.

Metode analisis data yang digunakan adalah analisis deskripsi kualitatif dengan mendeskrispkan kelima tahapan proses pengambilan keputusan konsumen rumah tangga dalam pembelian bumbu giling basah dan analisis diskriptif kuantitatif digunakan untuk mencermati pola pembelian konsumen bumbu giling basah serta metode analisis faktor digunakan untuk menganalisis faktor dominan pembelian bumbu giling.

Variabel yang diamati adalah pendapatan rumah tangga (X1), pekerjaan (X2), jumlah anggota keluarga (X3), persepsi harga bumbu giling basah dengan barang yang diperoleh (X4), persepsi harga bumbu giling basah basah dengan harga bumbu giling basah sachet (X5), pengaruh orang lain (X6), pengaruh rasa (X7), warna produk (X8), aroma/bau produk (X9), kebersihan (X10), keramahan pedagang (X11), kepercayaan diri terhadap rasa bumbu giling basah (X12), dan kepercayaan diri dalam meracik bumbu sendiri (X13).

\section{HASIL DAN PEMBAHASAN}

Hasil penelitian menunjukkan bahwa sebagian besar yaitu 32,22 persen responden berada pada usia 31-40 tahun, di mana secara demografi kelompok usia 15-64 tahun merupakan kelompok usia produktif (Mantra 2004). Hal ini menggambarkan bahwa rata-rata pembeli bumbu giling basah adalah ibu rumah tangga yang masih tergolong usia produktif, di mana ibu rumah tangga dalam usia tersebut masih aktif bekerja, sehingga lebih dominan mengonsumsi bumbu giling basah yang lebih praktis. Tingkat pendidikan responden mayoritas tamatan Sekolah Menengah (SMA) yaitu sebesar 61,11 persen. Mayoritas pekerjaan responden adalah ibu rumah tangga $(75,56 \%)$. Tingkat pendapatan rumah tangga yaitu sebesar Rp2.500.000,00-Rp3.500.000,00 per bulan di mana responden tergolong dalam golongan menengah yang sebagian besar jumlah anggota rumah tangga sebanyak $4-5$ orang $(55,56 \%)$.

Berdasarkan hasil wawancara dengan pedagang bumbu giling basah yaitu Ibu Sulis dari Pasar Pasir Gintung, Bapak Gunawan dari Pasar Tugu dan Bapak Sujarwo dari Pasar Cimeng, ketiga pedagang mengatakan bahwa ukuran bumbu giling basah yang paling banyak diminati konsumen adalah ukuran rupiah yaitu Rp2.000,00, Rp3.000,00, dan Rp5.000,00. Setelah dilakukan penimbangan dengan timbangan digital didapat hasil secara berturut-turut yaitu 77 gram, 103 gram dan 145 gram. Komposisi bumbu giling basah rendang, sayur santan dan ungkep menurut Ibu Sulis, Bapak Gunawan dan Bapak Sujarwo tidak jauh berbeda yang membedakan hanya komposisi bumbu rendang Ibu Sulis dan Bapak Gunawan tidak menggunakan kapulaga sedangkan Bapak Sujarwo menggunakan kapulaga. Berikut adalah komposisi bumbu giling basah rendang, sayur santan dan ungkep :

a) bumbu rendang : bawang merah, bawang putih, cabai merah, kayu manis, laos, sereh, jahe, cengkeh, kemiri, biji pala, dan merica.

b) bumbu sayur santan : bawang merah, bawang putih, cabai merah, kunyit, lengkuas, sereh, jahe, kemiri.

c) bumbu ungkep : bawang merah, bawang putih, ketumbar, kemiri, kunyit, lengkuas, jahe, daun salam dan daun jeruk.

\section{Tahap-tahap Pengambilan Keputusan dalam Membeli Bumbu Giling Basah}

Responden dalam memutuskan untuk membeli bumbu giling basah melalui lima tahap yaitu pengenalan kebutuhan, pencarian informasi, evaluasi alternatif, keputusan pembelian dan evaluasi pasca pembelian. Pada tahap pengenalan kebutuhan dilihat bahwa manfaat yang dicari konsumen adalah ingin lebih mudah dan praktis, hal ini ditunjukkan oleh 69 orang $(57,50 \%)$ ibu rumah tangga mencari manfaat tersebut dan alasan ibu rumah tangga dalam membeli bumbu giling basah juga karena ingin lebih mudah dan praktis yang ditunjukan oleh 73 orang $(73,00 \%)$ memilih alasan tersebut. Pada tahap pencarian informasi dapat dilihat bahwa yang pertama kali mempengaruhi ibu rumah tangga dan darimana ibu rumah tangga pertama kali mendapatkan informasi 
mengenai bumbu giling basah dan harganya adalah dari diri sendiri. Hal tersebut terjadi dikarenakan tidak adanya iklan mengenai bumbu giling basah dan ibu rumah tangga dapat mengetahui secara langsung harga bumbu giling basah dari pedagang bumbu giling basah, serta ibu rumah tangga melihat langsung bumbu giling basah saat belanja ke pasar.

Berdasarkan hasil wawancara yang telah dilakukan diketahui bahwa yang menjadi fokus utama ibu rumah tangga dalam membeli bumbu giling basah adalah kebersihan dari bumbu giling basah dan lingkungan pasar. Hal ini ditunjukkan oleh 47 orang $(41,96 \%)$ ibu rumah tangga menganggap kebersihan adalah hal terpenting ketika ingin membeli bumbu giling basah. Selain kebersihan, rasa juga menjadi fokus utama ke dua ketika ingin membeli bumbu giling basah. Rasa menjadi fokus kedua setelah kebersihan yang di mana jumlah responden yang memilih rasa tidak jauh berbeda dengan jumlah responden yang memilih kebersihan yaitu sebanyak 44 orang $(39,29 \%)$ ibu rumah tangga. Hal tersebut menunjukkan bahwa rasa juga menjadi fokus utama dalam membeli bumbu giling basah. Penelitian ini sesuai dengan penelitian yang dilakukan Delila, Indriani, dan Situmorang (2015) yang menyatakan bahwa atribut rasa dari saus sambal botol menjadi urutan pertama dalam pertimbangan ibu rumah tangga membeli saus sambal botol.

Setelah memiliki informasi yang cukup mengenai bumbu giling basah, ibu rumah tangga akan mengevaluasi berbagai alternatif yang ada dan membuat pertimbangan sebelum melakukan pembelian bumbu giling basah. Hal-hal yang membuat ibu rumah tangga memutuskan untuk membeli bumbu giling basah adalah cita rasa bumbu giling. Hal ini ditunjukkan oleh 58 orang $(59,79 \%)$ ibu rumah tangga memilih pilihan cita rasa bumbu giling basah dan diikuti hanya ingin mencoba serta lokasi yang mudah dicapai. Sama halnya dengan hal-hal yang membuat ibu rumah tangga memutuskan untuk membeli bumbu giling basah, atribut yang menjadi pertimbangan ibu rumah tangga untuk membeli bumbu giling basah adalah rasa dengan jumlah responden yang memilih atribut rasa sebanyak 57 orang atau sebesar 45,24 persen dan diikuti dengan aroma/bau, warna, dan harga bumbu giling basah. Hal ini sesuai dengan penelitian Delila et al. (2015) yang menyatakan bahwa rasa dan warna merupakan atribut yang menjadi pertimbangan konsumen ketika membeli saus sambal botol. Hal tersebut terjadi dikarenakan berdasarkan hasil wawancara ibu rumah tangga menganggap rasa bumbu giling basah sangat memengaruhi rasa masakan sehingga ibu rumah tangga menjadikan atribut rasa menjadi atribut yang dipertimbangkan ketika membeli bumbu giling basah.

Setelah melakukan tahap evaluasi alternatif, tahapan selanjutnya adalah tahap keputusan pembelian terhadap bumbu giling basah. diketahui bahwa mayoritas frekuensi ibu rumah tangga dalam membeli bumbu giling basah dalam satu minggu adalah 1-2 kali dengan jumlah responden 75 orang atau sebesar 83,33 persen sedangkan untuk frekuensi 3-4 kali dalam satu minggu hanya sebanyak 12 orang ibu rumah tangga atau sebesar 13,33 persen dari 90 responden. Hal tersebut terjadi karena ibu rumah tangga hanya akan membeli bumbu giling basah ketika merasa perlu dan tidak selalu ibu rumah tangga membeli jenis bumbu giling basah yang sama pada satu minggu tersebut. Jenis bumbu giling basah yang paling banyak dibeli oleh ibu rumah tangga adalah bumbu rendang dengan jumlah responden sebanyak 60 orang atau sebesar 38,96 persen dan diikuti oleh bumbu sayur santan, ungkep dan opor.

Tahap terakhir dari proses pengambilan keputusan adalah evaluasi pasca pembelian. Berdasarkan hasil penelitian, sebanyak 43 orang ibu rumah tangga atau sebesar 47,78 persen merasa cukup puas setelah membeli bumbu giling basah. Sebagian besar faktor yang mempengaruhi kepuasan ibu rumah tangga dalam mengonsumsi bumbu giling basah adalah rasa yang enak dan diikuti dengan ukuran/takaran yang didapat oleh ibu rumah tangga, kebersihan dan harga yang murah. Selain faktor yang mempengaruhi kepuasan ibu rumah tangga terdapat juga faktor yang mempengaruhi ketidakpuasan ibu rumah tangga yaitu rasa dari bumbu giling basah di mana beberapa ibu rumah tangga mengeluhkan rasa dari bumbu giling basah itu sendiri yang masih terasa kurang dan harus ditambah lagi beberapa macam bumbu untuk memperkuat rasa masakan.

\section{Pola Pembelian Bumbu Giling Basah}

Pola pembelian bumbu giling basah dalam penelitian ini dilihat dari jumlah, jenis dan frekuensi pembelian bumbu giling basah yang dilakukan konsumen. Jenis bumbu giling basah yang menjadi fokus dalam penelitian ini adalah bumbu rendang, bumbu sayur santan dan bumbu ungkep. 
Tabel 1. Sebaran konsumen berdasarkan jumlah pembelian bumbu giling basah dalam satu minggu terakhir di Kota Bandar Lampung

\begin{tabular}{cccr}
\hline No. & $\begin{array}{c}\text { Jumlah bumbu giling } \\
\text { basah (Rp) }\end{array}$ & $\begin{array}{c}\text { Jumlah } \\
\text { responden } \\
\text { (orang) }\end{array}$ & $(\%)$ \\
\hline 1. & $2.000,00-5.500,00$ & 68 & 75,56 \\
2. & $5.600,00-9.100,00$ & 14 & 15,56 \\
3. & $9.200,00-13.000,00$ & 8 & 8,88 \\
\hline & Total & 90 & 100,00 \\
\hline
\end{tabular}

Terdapat beberapa macam jenis bumbu giling basah yang juga dibeli konsumen dalam penelitian ini mulai dari opor, soto, cabai giling dan lain-lain. Berdasarkan hasil penelitian diketahui bahwa jenis bumbu giling basah yang paling banyak dibeli pada satu minggu terakhir adalah bumbu rendang dengan persentase 32,31 persen atau sebanyak 42 ibu rumah tangga, di mana bumbu rendang tersebut dikombinasikan dengan jenis bumbu giling basah yang lain seperti sayur santan, ungkep, dan opor dan jenis bumbu giling basah yang paling sedikit dibeli adalah bumbu pindang yaitu sebesar 0,77 persen.

Jumlah pembelian bumbu giling basah yang dilakukan oleh responden dalam penelitian ini cukup beragam. Sebaran responden berdasarkan jumlah pembelian bumbu giling basah di Kota Bandar Lampung dapat dilihat pada Tabel 1. Jumlah minimal pembelian bumbu giling basah oleh rumah tangga dalam satu minggu terakhir adalah sebesar Rp2.000,00 dengan jenis bumbu giling basah yang dibeli adalah bumbu sayur santan, rendang, ungkep, opor, dan soto dan jumlah maksimal pembelian bumbu giling basah oleh ibu rumah tangga dalam satu minggu terakhir adalah Rp13.000,00 dengan jenis bumbu giling basah yang dibeli adalah rendang, opor dan cabai giling. Jumlah pembelian bumbu giling basah yang paling banyak dibeli ibu rumah tangga dalam satu minggu terakhir adalah Rp2.000,00Rp5.500,00 dengan jumlah konsumen sebanyak 68 ibu rumah tangga $(75,56 \%)$.

Frekuensi pembelian responden terhadap bumbu giling basah berkaitan dengan kepentingan responden dalam mengonsumsi bumbu giling basah. Responden dalam penelitian ini menyatakan bahwa dalam satu minggu melakukan beberapa kali pembelian bumbu giling basah. Sebagian besar ibu rumah tangga melakukan pembelian bumbu giling basah sebanyak 1-2 kali dalam satu minggu terakhir yaitu sebanyak 81 orang ibu rumah tangga atau sebesar 90,00 persen. Frekuensi pembelian bumbu giling basah diduga sama dengan frekuensi ibu rumah tangga ketika berbelanja di pasar tradisional.

\section{Faktor Dominan Pembelian Bumbu Giling Basah dalam Rumah Tangga}

Faktor-faktor yang mempengaruhi pembelian bumbu giling basah pada konsumen di pasar tradisional dianalisis menggunakan analisis faktor. Analisis faktor dilakukan dengan metode ekstraksi Principal Component Analysis (PCA). Analisis faktor bertujuan untuk menyederhanakan bentuk hubungan antara beberapa variabel yang diteliti menjadi sejumlah faktor baru yang lebih sedikit (Sulisyanto 2005). Analisis faktor dikatakan layak apabila besaran/nilai Keiser-Meyers-Oklin (KMO) Measure of Sampling Adequacy $\geq 0,5$ serta tingkat signifikansi di bawah 0,05 (Supranto 2004). Dalam penelitian ini menghasilkan nilai KMO sebesar 0,710 dan nilai MSA masing-masing variabel di atas 0,5 dengan tingkat signifikansi 100 persen, artinya bahwa semua variabel dan data penelitian layak dianalisis menggunakan analisis faktor dan dapat dianalisis lebih lanjut. Setelah semua variabel dinyatakan layak untuk dianalisis lebih lanjut, maka variabel- variabel tersebut akan diekstraksi dengan menggunakan metode Principal Component Analysis (PCA).

Penentuan jumlah kemungkinan faktor terbentuk dapat dilihat dari nilai tabel total varian explained (Tabel 2). Nilai eigenvalue pembentuk faktor harus lebih atau sama dengan satu. Setelah dilakukan analisis, ternyata hanya terdapat 3 (tiga) komponen yang terbentuk dilihat dari nilai eigenvalues $\geq 1$. Komponen yang mewakili jumlah variabel independen dengan initial eigenvalues yang ditentukan bernilai 1 yaitu faktor pertama yang mempunyai eigenvalue 2,91, faktor kedua dengan nilai eigenvalue 1,26, dan faktor ketiga sebesar 1,18.

Setelah jumlah faktor terbentuk, maka variabelvariabel yang telah diekstraksi sebelumnya didistribusikan ke masing-masing komponen berdasarkan nilai faktor loading. Factor loading menunjukkan tingkat keeratan suatu variabel terhadap faktor yang terbentuk. Nilai factor loading yang dimasukkan ke dalam suatu komponen harus lebih besar dari 0,50. Nilai factor loading komponen matriks dapat dilihat pada Tabel 3. 
Tabel 2. Nilai Total Variance Explained (Initial Eigenvalues) analisis faktor

\begin{tabular}{|c|c|c|c|c|}
\hline No. & Komponen & Total & $\begin{array}{l}\text { Varian } \\
(\%)\end{array}$ & $\begin{array}{l}\text { Kumulatif } \\
(\%)\end{array}$ \\
\hline 1. & $\begin{array}{l}\text { Persepsi harga bumbu } \\
\text { giling basah dgn } \\
\text { barang yang } \\
\text { diperoleh }\end{array}$ & 2,91 & 29,06 & 29,06 \\
\hline 2. & $\begin{array}{l}\text { Persepsi harga bumbu } \\
\text { giling basah dengan } \\
\text { harga bumbu giling } \\
\text { sachet }\end{array}$ & 1,26 & 12,58 & 41,64 \\
\hline 3. & Pengaruh orang lain & 1,18 & 11,77 & 53,40 \\
\hline 4. & Pengaruh rasa & 0,93 & 9,33 & 62,74 \\
\hline 5. & $\begin{array}{l}\text { Warna bumbu giling } \\
\text { basah }\end{array}$ & 0,81 & 8,09 & 70,82 \\
\hline 6. & $\begin{array}{l}\text { Aroma bumbu giling } \\
\text { basah }\end{array}$ & 0,76 & 7,65 & 78,48 \\
\hline 7. & Kebersihan & 0,71 & 7,13 & 85,61 \\
\hline 8. & Keramahan pedagang & 0,58 & 5,77 & 91,39 \\
\hline 9. & $\begin{array}{l}\text { Kepercayaan diri } \\
\text { terhadap rasa bumbu } \\
\text { giling basah }\end{array}$ & 0,46 & 4,61 & 95,99 \\
\hline 10. & $\begin{array}{l}\text { Kepercayaan diri dlm } \\
\text { meracik bumbu } \\
\text { sendiri }\end{array}$ & 0,40 & 4,00 & 100,00 \\
\hline
\end{tabular}

Pada Tabel 3 dapat dilihat bahwa distribusi variabel pada tiap komponen batasan memiliki nilai factor loading yang tidak berbeda jauh dan belum tersebar secara merata sehingga perlu dilakukan rotasi agar distribusi jelas dan merata. Setelah dilakukan rotasi faktor (Tabel 4), maka distribusi variabel terlihat lebih jelas dan merata. Tiga komponen (faktor) baru yang sudah terbentuk akan diberi nama dan diinterpretasikan. Pemberian nama faktor tergantung dari nama-nama variabel yang menjadi satu kelompok, atau diambil berdasarkan nilai factor loading tertinggi.

\section{Komponen Satu (Faktor Pengaruh)}

Komponen pertama hasil analisis faktor terdiri dari variabel pengaruh orang lain, pengaruh rasa, warna bumbu giling basah, kepercayaan diri terhadap rasa bumbu giling basah dan kepercayaan diri dalam meracik bumbu sendiri. Hasil analisis menunjukkan bahwa variabel warna bumbu giling basah, pengaruh rasa, pengaruh orang lain, kepercayaan diri dalam meracik bumbu sendiri, dan kepercayaan diri terhadap rasa bumbu giling basah dapat mempengaruhi responden dalam membeli bumbu giling basah. Hasil penelitian
Juwita, Sayekti, dan Indriani (2015) menyatakan bahwa pengaruh rasa dan pengaruh orang lain menjadi faktor yang mempengaruhi konsumen dalam membeli bumbu instan.

\section{Komponen Dua (Faktor Persepsi)}

Komponen kedua hasil analisis faktor terdiri dari persepsi harga bumbu giling basah terhadap barang yang diperoleh, persepsi harga bumbu giling basah basah dengan harga bumbu giling basah sachet dan aroma bumbu giling basah yang disebut faktor persepsi.

Hasil analisis menunjukkan bahwa variabel persepsi harga bumbu giling basah dengan barang yang diperoleh, persepsi harga bumbu giling basah dengan harga bumbu giling basah sachet dan aroma/bau bumbu giling basah mempengaruhi responden dalam melakukan pembelian bumbu giling basah. Dengan demikian variabel-variabel tersebut dikategorikan dalam komponen dua. Hasil analisis Juwita et al. (2015) juga menyatakan variabel harga merupakan faktor utama ke dua yang mempengaruhi pembelian bumbu instan.

\section{Komponen Tiga (Faktor Tampilan dari Usaha Bumbu Giling Basah)}

Komponen umum ke tiga hasil analisis faktor diberi nama faktor tampilan dari usaha bumbu giling basah. Penamaan untuk komponen ketiga ini mencerminkan variabel-variabel yang ada pada komponen ketiga.

Tabel 3. Component Matrix tingkat keeratan variabel independen pada analisis factor

\begin{tabular}{llll}
\hline \multirow{2}{*}{ Variabel } & \multicolumn{4}{c}{ Komponen } \\
\cline { 2 - 5 } & 1 & 2 & 3 \\
\hline $\begin{array}{l}\text { Persepsi harga bumbu giling basah } \\
\text { dengan barang yang diperoleh }\end{array}$ & 0,44 & 0,46 & -0.38 \\
$\begin{array}{l}\text { Persepsi harga bumbu giling basah } \\
\text { dgn harga bumbu giling sachet }\end{array}$ & 0,52 & 0,28 & $-0,42$ \\
Pengaruh orang lain & 0,67 & $-0,18$ & $-0,06$ \\
Pengaruh rasa & 0,54 & $-0,46$ & 0,27 \\
Warna bumbu giling basah & 0,61 & $-0,46$ & $-0,13$ \\
Aroma bumbu giling basah & 0,57 & 0,28 & $-0,22$ \\
Kebersihan & 0,43 & 0,53 & 0,56 \\
$\begin{array}{l}\text { Keramahan pedagang } \\
\text { Kepercayaan diri terhadap rasa }\end{array}$ & 0,54 & 0,20 & 0,60 \\
bumbu giling basah & 0,56 & $-0,08$ & $-0,20$ \\
$\begin{array}{l}\text { Kepercayaan diri dalam meracik } \\
\text { bumbu sendiri }\end{array}$ & 0,45 & $-0,33$ & 0,08 \\
\hline
\end{tabular}


Tabel 4. Nilai Rotated Component Matrix analisis faktor dominan dalam pembelian bumbu giling basah di Kota Bandar Lampung

\begin{tabular}{|c|c|c|c|}
\hline \multirow{2}{*}{ Variabel } & \multicolumn{3}{|c|}{ Komponen } \\
\hline & 1 & 2 & 3 \\
\hline $\begin{array}{l}\text { Persepsi harga bumbu giling } \\
\text { basah dengan barang yang } \\
\text { diperoleh }\end{array}$ & $-0,04$ & 0,73 & 0,09 \\
\hline $\begin{array}{l}\text { Persepsi harga bumbu giling } \\
\text { basah dengan harga bumbu giling } \\
\text { sachet }\end{array}$ & 0,14 & 0,71 & 0,01 \\
\hline Pengaruh orang lain & 0,60 & 0,34 & 0,13 \\
\hline Pengaruh rasa & 0,73 & $-0,09$ & 0,21 \\
\hline Warna bumbu giling basah & 0,74 & 0,21 & $-0,08$ \\
\hline Aroma bumbu giling basah & 0,18 & 0,62 & 0,19 \\
\hline Kebersihan & $-0,03$ & 0,19 & 0,86 \\
\hline Keramahan pedagang & 0,28 & 0,06 & 0,78 \\
\hline $\begin{array}{l}\text { Kepercayaan diri terhadap rasa } \\
\text { bumbu giling basah }\end{array}$ & 0,43 & 0,42 & 0,03 \\
\hline $\begin{array}{l}\text { Kepercayaan diri dalam meracik } \\
\text { bumbu sendiri }\end{array}$ & 0,55 & 0,04 & 0,08 \\
\hline
\end{tabular}

Variabel-variabel yang termasuk dalam faktor ini adalah kebersihan dan keramahan pedagang. Hasil analisis ini menunjukkan bahwa variabel kebersihan dan keramahan pedagang mempengaruhi responden dalam memutuskan membeli bumbu giling basah. Hasil penelitian Adiyoga (2011) menyatakan bahwa faktor memengaruhi pengambilan keputusan konsumen dalam pembelian bawang merah dan cabai merah yaitu kualitas produk seperti kesegaran (tidak ada tanda busuk) dan kebersihan produk.

\section{KESIMPULAN}

Tahap-tahap pengambilan keputusan pembelian bumbu giling basah oleh ibu rumah tangga terdiri dari ibu rumah tangga ingin mudah dan praktis, dengan mencari informasi sendiri, di mana rasa menjadi pertimbangan utama ketika memutuskan membeli bumbu giling basah, dan keputusan pembelian tergantung keadaan dengan frekuensi pembelian bumbu giling basah sebanyak 1-2 kali dalam satu minggu dengan jenis bumbu giling basah terbanyak yaitu bumbu rendang, responden merasa cukup puas dengan rasa, harga, ukuran/takaran dan kebersihan tempat dan responden akan melakukan pembelian berulang. Pola pembelian bumbu giling basah oleh ibu rumah tangga yaitu jumlah bumbu giling basah yang dibeli dalam satu minggu terakhir adalah Rp2.000,00-Rp5.500,00 dengan jenis bumbu giling basah yang paling banyak dibeli adalah bumbu rendang dengan frekuensi pembelian sebanyak 1-2 kali dalam satu minggu terakhir. Faktor dominan keputusan pembelian bumbu giling basah di Kota Bandar Lampung dibentuk berdasarkan tiga komponen utama (faktor) berdasarkan nilai factor loading. Komponen pertama (faktor pengaruh) terdiri atas variabel warna bumbu giling basah, pengaruh rasa, pengaruh orang lain, kepercayaan diri dalam meracik bumbu sendiri dan kepercayaan diri terhadap rasa bumbu giling basah. Komponen ke dua (faktor persepsi) terdiri dari variabel persepsi harga bumbu giling basah terhadap barang yang yang diperoleh, persepsi harga bumbu giling basah basah terhadap harga bumbu giling basah sachet dan aroma/bau bumbu giling basah. Komponen ke tiga (faktor tampilan dari usaha bumbu giling basah) terdiri dari variabel kebersihan dan keramahan pedagang.

\section{DAFTAR PUSTAKA}

Adiyoga W. 2011. Faktor-fakor yang mempengaruhi perilaku dan keputusan konsumen untuk membeli kentang, bawang merah, dan cabai merah. J.Hort, 21(3): 280294.

https://media.neliti.com/media/publications/82 015-none-b0836fb9.pdf. [20 Juli 2019].

BPS [Badan Pusat Statistik] Provinsi Lampung. 2017. Pola Konsumsi Penduduk Provinsi Lampung. https://lampung.bps.go.id/publicat ion/2018/04/25/ae27fa7cdef55bafc892baca/po la-konsumsi-penduduk-provinsi-lampung-201 7.html. [1 November 2018].

Cohen L, Manion L dan Morrison K. 2007. Research Methods in Education. Sixth Edition. Routledge. New York

Delila S, Indriani WD, dan Situmorang S. 2015. Pengambilan keputusan rumah tangga dalam membeli saus sambal botol di Bandar Lampung. Jurnal Ilmu Ilmu Agribisnis, 3 (1): 100-106. http://jurnal.fp.unila.ac.id/index.php/JIA/articl e/view/1023/928. [20 Juli 2019]

Juwita A, Sayekti WD, dan Indriani Y. 2015. Sikap dan pola pembelian bumbu instan kemasan oleh konsumen rumah tangga di Bandar Lampung. Jurnal Ilmu Ilmu Agribisnis, 3(3): 329-335.

http://jurnal.fp.unila.ac.id/index.php/JIA/articl e/view/1059/964. [20 Juli 2019].

Kotler P. 2005. Manajemen Pemasaran. Edisi Kesembilan. PT Indeks Kelompok Gramedia. Jakarta.

Mantra IB. 2004. Demografi Umum. Penerbit Pustaka Pelajar. Yogyakarta. 
Jurnal Ilmu Ilmu Agribisnis: Journal of Agribusiness Science, 9(1), Februari 2021

Prihastuti E, Komariah K, dan Purwanti S. 2008. Restoran untuk SMK (Direktorat Pembinaan Sekolah Menengah Kejuruan). Departemen Pendidikan Nasional. Jakarta.

Singarimbun M dan S Effendi. 2006. Metode Penelitian Survei (Editor). LP3ES.
Jakarta.Sulisyanto B. 2005. Analisis Data dalam Aplikasi Pemasaran. PT. Ghalia Indonesia. Bogor.

Supranto J. 2004. Analisis Multivariat : Arti dan Interpretasi. Rineka Cipta. Jakarta. 